\title{
浅谈无公害蔬菜病虫害农业防治技术
}

\author{
党鹏 李忱 李中周
}

安阳市农业科学院

DOI:10.32629/as.v1i2.1457

[摘 要] 无公害蔬菜主要指有害物质不超标, 食用后不会对人体健康造成危害的蔬菜。为了保障无公害蔬菜达到国家规定标 准,对其病虫害防治,必须因地制宜的坚持以农业防治与生物、物理防治相结合为主,化学农药防治为辅的无害化防治原则。基 于此, 本文阐述了无公害蔬菜病虫害的主要特征以及无公害蔬菜病虫害的非农业防治技术,对无公害蔬菜病虫害防治存在的主 要问题与农业防治技术进行了探讨分析。

[关键词] 无公害蔬菜; 病虫害; 特征; 防治问题; 农业防治技术

随着社会经济的快速发展, 人们对物质生活要求也不断 提高, 特别对食品品质要求。其中无公害蔬菜减少了原来由 于过度使用化学产品造成的蔬菜污染问题, 日益受到人们青 睐。但是无公害蔬菜在种植过程中一般会出现病虫害现象, 因此为了保障无公害蔬菜种植的有效性, 以下就无公害蔬菜 病虫害农业防治技术进行了探讨分析。

\section{1 无公害蔬菜病虫害的主要特征分析}

无公害蔬菜病虫害的特征主要有:（1）无公害蔬菜病虫 害类别多且危害大。据相关研究, 目前无公害蔬菜常年发生 的病害有四十多种, 基本上所有蔬菜都有可能受到病虫害的 影响, 据相关统计分析, 受病害的无公害蔬菜产量一般会降 低 $10 \% \sim 15 \%$, 严重的有可能绝收, 所以说无公害蔬菜病虫害 的危害非常大。(2) 无公害蔬菜病虫害受气候影响大。无公 害蔬菜病虫害在气候适宜时, 很容易暴发成灾, 并且防治难 度非常大, 如辣椒疫病等。(3) 演替变更日趋复杂。基于无公 害蔬菜生产的周年特征, 使得病虫害产生的规律也得到改变, 比如过去有些季节性病虫危害演变成周年危害, 使得防治变 得非常困难。并且过去有些次要病虫害, 基于各种因素的影 响, 使其变更为主要病虫害等现象。

\section{2 无公害蔬菜病虫害的非农业防治技术分析}

无公害蔬菜病虫害的非农业防治技术主要有物理防治、 化学防治及生物防治, 具体表现为: (1) 物理防治技术。可以 设置防虫网、遮阳网进行病害的防治, 该种措施对温室大棚 蔬菜的作用比较明显, 能够及时阻止病害侵入, 进而实现发 病率的降低。其中, 遮阳网能够避免蔬菜受到阳光的直射, 同时实现防病害的目的。此外黄板诱杀、薄膜覆盖、设置杀 虫灯均属于较为典型的病虫害物理防治手段, 其中黄板诱杀 一般通过悬挂黄板实现翅蚜等害虫的处理, 而薄膜覆盖则具 备驱蚜防病效用, 设置杀虫灯则可有效诱杀银纹夜蛾、菜蛽、 斜纹夜蛾等害虫。(2) 化学防治技术。无公害蔬菜种植不是 完全不使用农药, 而是将使用的化学药剂控制在一定的合理 的范围内, 符合国家规定的要求。无公害蔬菜生产中的病虫 害化学防治多使用化学试剂进行种子处理, 农药的使用也属 于化学防治范畴, 但为了保证无公害蔬菜的品质, 农业人员
必须做到科学用药, 如无公害油菜生产中可使用少量霜霉威 水剂、百菌清、杀毒矾防治霜霉病与白锈病 (早春始病期和 抽荎开花期), 且这一过程做好药量的控制。(3) 生物防治技 术。具体表现为: 第一、天敌防治。天敌防治属于最为经济、 有效的生物防治技术, 捕食性天敌蜘蛛、寄生性天敌赤眼蜂 等均属于其中代表。第二、病毒防治。一些特定病毒具备消 灭蔬菜病虫害的能力, 如斜纹夜蛾核型多角体病毒可用于叶 菜类虫害防治、颗粒体病毒可用于斜纹夜蛾和菜青虫的防 治。此外使用病毒制剂进行蔬菜种子的处理同样能够有效预 防病虫害, 黄瓜病害的预防便可以使用细胞分裂素增产菌进 行种子处理。第三、抗生菌、抗生素防治。无公害蔬菜生产 中也可以使用抗生菌、抗生素防治病虫害, 如汶阳霉素可作 为螨药物使用, 武夷菌素则可用于灰霉病、瓜类病害防治。

\section{3 无公害蔬菜病虫害防治存在的主要问题}

无公害蔬菜病虫害防治存在的问题主要有: (1) 技术力 量问题。无公害蔬菜生产要求技术含量高, 如果没有足够数 量的技术人员进行指导, 将会制约其产量。但是基于目前农 村基层的农业技术人员严重不足及无公害技术杀虫板、防虫 网、生物农药等不能得到推广的现状, 降低了无公害蔬菜产 量。(2)农药市场缺乏有效监管的问题。在无公害蔬菜生产 过程中, 由于缺乏对农药市场缺乏有效监管, 为了牟取利润, 有些农药销售人员误导菜农用药, 导致蔬菜的农药残留问题 得不到改善。(3)农药应用不合理的问题。有些菜农不能正 确识别病虫害, 经常错过病虫害的防治时机。有些菜农对农 药使用的次数和浓度、药剂的选择使用难以准确把握, 误用 和不合理使用农药现象非常多, 导致无公害蔬菜的农药污染 问题非常严重, 从而影响无公害蔬菜的产量及其安全。

\section{4 无公害蔬菜病虫害农业防治技术分析}

农业防治技术一般源于各地区长期开展的农业生产实 践, 目前无公害蔬菜病虫害农业防治技术, 笔者认为主要有: (1) 合理选择生产基地。无公害蔬菜生产基地选择要求在没 有污染。评价污染内容主要有: 土壤方面的重金属污染等; 大气方面的 S02、CH4 和氟化物等; 水源方面有机物、营养 物、细菌和大肠杆菌等; 化肥方面的氮肥、硝酸盐含量是否 
超标等。(2) 深耕晒栠。蔬菜播种前的深耕可将病菌、虫卵 翻至土壤表面, 在阳光暴晒、恶劣天气、天敌等自然条件作 用下, 蔬菜的病虫害阿生概率将大大下降。(3) 土壤杀菌。高 温、低温均可用于土壤病原、虫卵的处理, 夏季可通过地表 覆膜进行浅层、表层土壤的病原处理, 而冬季则可翻松表层 土壤冻杀相关细菌、虫卵。(4) 种子处理。蔬菜播种前的种 子处理可有效预防多种病虫害的发生, 如在 $70^{\circ} \mathrm{C}$ 条件下进行 种子 (水分含量不高于 $70 \%$ ) 40min 的干热处理, 即可有效预 防蔓枯病菌、黑星病菌、炭疽病菌并病害的发生, 同时种子 的出芽率、活力指数基本不会受到影响。此外, 温汮浸种消 毒也属于较为常见、有效的种子处理措施。(5) 加强无病虫 壮苗的培养。由于育苗质量直接影响到无公害蔬菜产量, 因 此为了提高无公害蔬菜产量, 必须加强无病虫壮苗的培养。 并且无病虫危害是衡量育苗质量的重要指标。(6)科学运用 轮作、间作、套种等技术体系。耕作综合技术体系是无公害 蔬菜生产的基本原则。无公害蔬菜生产过程中, 需要科学合 理的运用耕作综合技术体系: 禁止同科、属、种轮作; 利用 化感原理, 注意间作、套种, 提高土壤利用率; 合理进行土壤 休闲和耕翻; 换茬期间深翻晒垈和冻袋, 减少土壤病虫害残 留, 增加土壤肥力; 协调好用地和养地的关系。(7) 播种期需 要避开病虫害发生的高峰期。无公害蔬菜播种可避开病虫害 高发期, 开展多品种蔬菜轮种、灵活使用喷灌或滴管等现代 浇灌方法、开展作物套种等也将较好降低病虫害的严重程 度。并且在无公害蔬菜生产过程中, 由于不同季节, 温、光、 湿、气等生产环境因素不同, 无公害蔬菜的病虫害状况也不 同。因此播种期不仅要充分考虑到对经济收益的影响, 还要 考虑病虫害对产品质量的影响。(8) 加强菜田结构的优化。 优化菜田结构, 改善通风透光条件, 可以减轻病虫危害。第 一、合理密植。无公害蔬菜生产提倡适度稀植, 通过植株调 整等技术措施创造合理的群体结构, 从而改善其生长环境, 增强植株群体抗病虫能力。第二、吊蔓或支架。合理应用吊 蔓或支架, 目的是为了充分利用空间和光热资源; 改善冠层 内通风、透光条件, 减轻病虫危害。(9) 严格无公害蔬菜生产 设施环境的调控。无公害蔬菜生产设施环境主要包括温度、 光照、湿度和气体等。合理控制环境湿度、温度同样可用于 无公害蔬菜病虫害农业防治, 特别是温室大棚中栽植的无公 害蔬菜, 农业人员可采用紫外隔膜抑制灰霉病菌繁殖, 蔬菜
出现黑星病菌繁殖情況, 则可通过闷棚 $\left(50^{\circ} \mathrm{C}\right.$ 以下、 $70 \%$ 湿度 以上) 进行处理。并且严格无公害蔬菜生产设施环境的调控, 可以保证植株健壮生长, 提高植株抗逆性, 是无公害蔬菜病 虫害农业防治的重点内容。第一、温度调控。任何环境因素 的调控都必须在满足作物温度要求的前提下进行, 避免发生 高温或低温障碍。第二、光照调控。光照调控是在满足无公 害蔬菜温度要求的前提下, 尽可能增加光照强度, 延长光照 时间。第三、湿度调控。空气湿度也是造成多种病虫害, 尤 其是真菌性病害发生的主要因素。调控空气湿度的措施主要 有以下两方面: 一是覆盖地膜: 减少地表水分蒸发和浇水量, 降低空气湿度; 二是加强通风: 在保证温度要求的前提下, 尽可能增加通风量和通风时间, 达到散湿、换气、排散毒害 气体等效果。此外, $\mathrm{C} 02$ 作为植物光合作用原料, 其浓度高低 直接影响到作物叶片光合效率, 并进而影响到植株长势和抗 逆性, 以及无公害蔬菜的产量。

\section{5 结束语}

综上所述, 无公害蔬菜种植过程中, 为了提高无公害蔬 菜质量及其经济效益, 要求对无公害蔬菜病虫害进行科学防 治, 同时贯彻预防为主, 防治结合的方针, 并且对其存在的问 题进行分析, 合理应用农业防治技术, 从而保证无公害蔬菜 符合国家规定标准。

\section{[参考文献]}

[1]张瑞芳,王菲.绿色无公害蓅菜病虫害防治技术 [J].中 国农业信息,2016(24):111。

[2]单飞.设施农业病虫害的防治方法[J].吉林农业,2016(10):90.

[3]首成英.无公害蔬菜种植技术及病虫害防治措施分析 [J].农技服务,2017,34(13):42.

[4]刘恩宏.保护地无公害蔬菜病虫害综合防治技术的研 究[J].农业与技术,2018,38(08):57.

\section{作者简介:}

党鹏(1980--) 男, 河南安阳人, 研究实习员, 研究方向：农 技推广。

李忱(1988--)男, 河南安阳人, 研究实习员, 研究方向: 农 技推广。

李中周(1987--)男, 河南安阳人, 研究实习员, 研究方向: 农技推广。 